\title{
Problems and Prospects of Geoaesthetics
}

\author{
Kwang Myung Kim ${ }^{1,2}$ \\ ${ }^{1}$ Department of Philosophy, Soongsil University, Seou, South Korea \\ ${ }^{2}$ University of Virginia, Charlottesville, USA \\ Email: kmkim@ssu.ac.kr
}

Received 14 November 2014; revised 8 December 2014; accepted 26 December 2014

Copyright (C) 2015 by author and Scientific Research Publishing Inc.

This work is licensed under the Creative Commons Attribution International License (CC BY). http://creativecommons.org/licenses/by/4.0/

cc) (i) Open Access

\begin{abstract}
Geoaesthetics is the project of making aesthetic sense of nature through geological phenomena. The aesthetic appreciation of nature has recently become urgent because of the serious influence of the natural environment on human beings. The author's geoaesthetical research is categorized into three problems: art in geology or geology in the arts as the close relationship between art and geology, geological cognition of nature and natural cognition in environmental aesthetics, and the geoaesthetical approach through works of art. Geologic forces and processes have become significant materials for aesthetic sensations. Based on the geoaesthetic perspective, the author explores the ultimate purpose of art as a return to natural order. It seems partly to be related to the ontological problem of art. Here we can feel earthly dynamics, universal calmness, and the contemplative atmosphere simultaneously.
\end{abstract}

\section{Keywords}

Geoaesthetics, Geological Phenomena, Aesthetic Appreciation of Nature, Geoaesthetic Perspective

\section{Introduction}

To know the world has been one of the main tenets of philosophy since the advent of philosophical history. Although there are heated debates over the problems of knowing, we understand that it is closely linked to the problems of perceiving. According to an empirical standpoint, knowledge has its origins primarily in our sensual perceptions. Further common perceptions enhance our communicative competence and diminish the gaps between nature, art, and the sciences (Abbey \& William Fiero, 1986: xii-xiii). As far as we know the context of A. G. Baumgarten (1714-1762), the first giver of a scientific name, aesthetics is a study of sensuous cognition. "The topic of aesthetics is forms and possibilities of process oriented perception. Aesthetics is concerned with mode of perception” (Seel, 1998: p. 341). The cognitive has an influence on the sensuous. The cognitive and the sensuous affect each other (Saito, 2010: p. 382). Sensuous cognition plays a key role in the field of knowledge. 
So it is naturally related to the area of aesthetics. Since the so called ancient imitation theory of nature in art, we have experienced many theories and trends, such as formalism, expressionism, modernism, postmodernism, etc.

We are living in natural surroundings as well as cultural surroundings. Nature itself has offered us many materials for aesthetic sensations among our natural surroundings. Nature as the counterpart of finite man, marks, remarks, completes and renews man. We have a human project of making aesthetic sense of nature, for example geological phenomena. The contemplation of natural beauty is related, according to Kantian aesthetic theory, to the exercise of reflective aesthetic judgment (Shapiro, 2004: pp. 110-111). Besides, we accept the free play between the understanding of nature and aesthetic imagination. More precisely, instead of the free play it can be substituted as a suitable proportion between understanding and imagination. With the intervention of this proportional relation, imagination can keep up with understanding (Plessner, 1981: pp. 317-321). "Many cultures have a long-standing tradition regarding the aesthetic appreciation of nature and environment that is often inseparable from their general worldview” (Saito, 2010: p. 383).

Recently the aesthetic reappreciation of nature has become more urgent because of the serious influence of the natural environment on human beings. The natural environment is situated at the center of our daily lives, affecting us in global warming, air and soil pollution, tsunamis etc. Geological forces and processes are significant instruments for aesthetic sensations as well. Art has been an important way to appreciate geology. Geological phenomena bring aesthetic understanding and form an aesthetic concept. With this aesthetic concept artwork depicts geological features. Geoaesthetics will be a turning point for reorientation toward the threefold relation between human beings, art, and nature. Geoaesthetical approaches make us think about the basis for this threefold relation. Baumgarten isolated aesthetic perception as a kind of cognition. Specifically aesthetic cognition is foregrounded in the triadic relationships among geology, art and human beings.

Through geoaesthetical examination, the author will review the way art can contribute to the alleviation of today's deformed state of nature in natural catastrophes and ecological degredation, and restore harmonious coexistence with nature. According to Finnish geologist, Toni Eerola, geoaesthetics can be defined as aesthetics produced by natural geological processes, geological elements or concepts creating $\operatorname{art}^{1}$. The author is going to look for the sensuous presentations from the geoaesthetical perspective. Geological features are applied and arranged according to the character of aesthetic objects. The relationship of art and geology has been approached in painting, photography, poetry, sculpture, and performance, etc. The research and investigation of this relationship is included in the field of geoaesthetics. Geoaesthetics comprises various formations, structures and cleavages of rocks, minerals and outcrops, natural monuments, and landscapes. The use of rocks or other geological elements in decoration, and architecture are displayed in land or earth art. Especially in the fields of sculpture and installation we can see this linkage between earth and art. In ancient rock engravings we can observe that artists used geologic materials to create art. In the main discourse of the author he will provide definite examples for these trends, especially in painting, sculpture, and installation ${ }^{2}$.

For geoaesthetical research, the author has categorized three problems: art in geology or geology in arts as the close relationship between art and geology; geological cognition of nature and natural cognition in environmental aesthetics; and the geoaesthetical approach through works of art by Hongtae Kim, Soyoung Chung, Isamu Noguchi, and Maya Lin. Nature provides aesthetic sensation in all of us. It enlarges the fields of our aesthetic experiences. Geological forces and their appearances are efficient materials and instruments for aesthetic expression in the context of invisible vitality and various vital figures. We admire and appreciate beautiful landscapes originating from wonderful minerals, fossils, volcanic eruptions, icebergs, sedimentation, erosion, natural monuments, etc. All these evoke in us aesthetic sensation and the perception that we can have distinctive experiences. We can use these aesthetic objects in architectural decoration, sometimes as land or earth art. Viewed in the relational context of art and geology we can apply geoaesthetical approaches to painting, photography, poetry, sculpture, installations, performance, film, and many other artistic fields. We can consider all of these within the category of geoaesthetics. In geoaesthetics, geological elements, concepts and processes can be expressed and represented. In connection with empathy, self-expression, and self-knowledge we can consider the relation between the expression and the expressed in nature. And finally we can remove the gap between human being, art, and nature (cf. Green, 2008).

${ }^{1}$ cf. http://www.progeo.se/news/2008/pgn108.pdf (accessed 14 December 2012).

${ }^{2}$ Robert Smithson's earthwork, “Spiral Jetty” shows us earth moving. In addition, Bernhard Edmaier's “Geoart”, James Turrell’s “Roden Crater" as the site of an earthwork are good examples. 


\section{The Relationship between Art and Geology: Art in Geology or Geology in Arts}

In geoaesthetics it is important to consider how closely related art and geology are. Geoaesthetics combines art with geology. It unifies classical concepts of landscape and geological beauty with the perspective of microscope pictures, satellite images, and geological maps (For this Friedl et al., 2012). In landscape beauty, "landscape once meant a picture or painting of a view; then it came to mean the view itself” (Shapiro, 2004: p. 105). In evaluating or appreciating landscape, aesthetic sensibility and human activity are intertwined with each other. This problem is particularly motivated by the recognition of nature through the long history of art in the West and East, despite of some differences between them.

We need geoaesthetical understanding that moves from outer appearances to inner essentials. Geological mapping is produced from the observation of geological phenomena. Aesthetic reconstruction of this geological mapping like the rock cycle, earth figure, continental drift, gives us good material for aesthetic expression in painting, sculpture, and installation etc. For example in viewing the desert, "our perception of desert regions, where space abounds, makes us conscious of the brevity of human life and, in contrast, of unending time. For an artist, the plants, animals, rocks, and hills transform into visual elements of dark-light, surface textures, geometric and amorphous structures, colors, shapes-an array of contrasting images and suggestive interactions of space which intrigue, overpower, and precipitate creative ideas” (Abbey \& William Fiero, 1986: p. 19). The geologist reviews and integrates a myriad of rock details, and he has experience in viewing earth materials. On the other hand, the artist appreciates landscape itself and brings it to aesthetic formation. The origins of life wriggle beneath and within the desert rocks and soils, and finally come out for air. Ancient seeds are lying dormant below the surface of the earth. Here we can perceive the mystery and persistence of life. Life force is linked deeply with the root. The origin and end of life has been a long theme of the arts.

In this point we can consider the rock as the root of life. What's the meaning of rock in rock art? In rock art, rock has a symbolic image, sometimes produced as a part of ritual, manmade markings and carved features on to natural stone. The creation of rock art was itself a shamanistic and ritual act. In confrontation with the enormity of nature, rock played a magic role to console the human being for his finiteness and incompetency. Rock art is integrated into the natural world in a way that few other humanly made objects have been. Marks on rocks as unique to rock art have become integrated into the natural site. The aesthetic appreciation of marks on rocks offers us an alternative model for the enjoyment of human creativity (Heyd, 2003: p. 43). Some prehistoric rock art may appear like abstract and symbolic art. We can read the aesthetic import of vital lives at that time in condensed and symbolized images. Aesthetic appreciation of rock art also calls for factual knowledge of rock. And to be fully appreciated, things need to be understood within aesthetic context in relation to human feelings and emotion.

Geologically speaking, a rock is a solid, cohesive aggregate of one or more mineral materials. As seeds of the earth, rocks are pressed upward in infinite regeneration. So rock is closely related to the age of the earth. "Massive geologic forces stir within the thermal cauldron, which lies a scant distance below the desert floor. The land heaves upward in spasmodic releases of energy. The earth, by its mass and size, generates internal heat energy to deform and crumple its thin crust” (Abbey \& William Fiero, 1986: p. 20). From this process, geological sediments produce various figures in layers, and also yield horizontal beds, which compose the demarcation between earth and sky. It is similar to the abstract linear composition in the case of all-over painting. The fragments of the earth are sliding, rolling, and flowing over the river or along the valley to the sea. Sometimes under the uncompromising pull of gravity these may be temporarily restrained by natural dams or lowland areas which in turn create beautiful landscapes ${ }^{3}$. Vertical forces of the earth are created by thermal instabilities, and are sometimes frozen into transitory parallel layers that are in disequilibrium. The parallel layers disrupt earlier forms, and various changes are produced from the deforming and reforming process, but, if there is no net gain or loss of material, layers can remain stable in equilibrium.

The layers of the earth are sliced by fractures that lie exposed to the action of surface erosion. Visually overwhelming in size and its intricate landscape show us picturesque grandeur. Huge walls are viewed aesthetically as relief structures and as murals which lend themselves to imaginative interpretations. The thick sequence of ancient rocks is exposed in the wall-layers and severances. They create shifting, sectional compositions as wide and high as vision allows us to encompass. The contrasts of stratified textures and stains exhibit nature's har-

\footnotetext{
${ }^{3}$ Various perceptual phenomena of the earth like this can be seen in the photos of Edmaier and Jung-Hüttl, 2008, Earthsong (New York:
} Phaidon). 
monic design despite of the various differences and transformations. Especially, mode of imaginative perception contributes to aesthetic interpretation. Such contrasts promote to fantasy and curiosity, as well as geological reality (Abbey \& William Fiero, 1986: p. 21). These contrasts show us dynamic changes of vision and form, and then balance.

Lava is a common product of volcanic eruptions, especially black lava which derives its capacity for light absorption from the complete mixing of its component colorful minerals. The structures of the lava flow can still be clearly seen. Molten rock, with its elements in the finest possible state and thoroughly diffused, abruptly pours out on to the cold land surface. After a few initial spurts of ash, lava begins to flow quietly from the craters (Edmaier \& Jung-Hüttl, 2008: p. 94). The use of black as the lone color in a work of art emphasizes the significance of texture, light, and form. It also acts as a unifying force and conjures multiple meanings. Inner tensions from dark depths come to life, pulsate, and enlarge under varied light conditions. Changing light also drastically alters form as it yields to surface contours. Volcanic rock is so prevalent in desert regions and becomes mirror like and glows luminously white in this environment. "Lava flows exhibit a wrapping aspect when a cooled or frozen exterior contains a still flowing molten interior. Nature, like some works of art, adds to our understanding of the roles of time, motion, and essence itself, thus moving us to larger perspectives of mental and visual balance" (Abbey \& William Fiero, 1986: p. 23). At this forming moment of the various geologic phenomena we can find the process of natural equilibrium. In other words, this equilibrium is related to the earthly balance of change and circulation.

With color itself and changes of color we can follow the process of expression and creation of dynamic tension, plasticity, depth, and forces that often thrust beyond the boundaries of the conscious. The geologic world contains a great deal of expressiveness which can be the ground for expression. Visual objects are full of expressiveness. Object's expressiveness derives from the artist's own self-expression. Exquisite color in the desert shows us the result of exploring, expressing, and energizing intangible forces. The artist sees colors with his entire organism through a complex personal process. The artist feels, generates, and rearranges pigment into visual fields which he strives to arrange with a sense of unity and harmony. "Color is the artist's vehicle, his way of relating to, transcending, and inventing his world” (Abbey \& William Fiero, 1986: p. 33). Various ranges of colors in desert landscapes or the desertification process reflect and verify attempts to achieve stability and equilibrium within an environment. Plants are not only producers of color, but are themselves sensitive to color. Desert soils are stabilized by processes-such as rainfall, temperature changes, and oxidation. Lines and wrinkles form along planes of weakness and the softer parts are collapsed or removed. The desert appears to be a quiet environment of well-adjusted rocks and plants. Climatic zones shift over time. Topography changes as global temperatures are changed (Montgomery, 1995: p. 192).

In a work of art, lines force the eye to explore surfaces and depths through movement, creating patterns of varied velocities. Lines are the equivalent of time for the geologist as well. Many geologic sections contain features referred to as time lines. Lines and planes play a role to form geo-construction or geo-building. The primordial, infinitely varied lines of profile or shift of the earth are as distinct as the unique lines of painting or sculpture. "The serpentine loops of a desert canyon resemble the trail of a sidewinder, the cracks which form in the mud of a drying desert arroyo look like the interconnecting plates of a desert tortoise shell, the branching of a tree seems to copy the branching of the tributaries of a desert wash eroding into a hill of soft mud. The artist may intuitively and coincidentally develop abstract motifs that already exist in nature: colors, shapes, textures, and patterns" (Abbey \& William Fiero, 1986: p. 53). And these elements like strata of rocks, patterns of plants, anatomical structures of animal, infinite arrangements of space and structure closely resemble those of the arts. These various changes are also similar to multi compositions of canvas in figurative art and installation. We are invited to consider material representation unifying art as humanistic activity and natural phenomena.

Geological texture of rock is characterized as the size, shape, and arrangement of components. This texture is applicable to the aesthetic contents. Stripped of plants or the presence of old eroded sediment, the desert surface portrays the power and omnipresence of gravity. Gravity as an attractive force and as a creator of spatiotemporal curvature, holds the fragments of the earth together. Textures are also inherent in the materials the artist uses. Textures increase tension, movement, and a wide range of contrast. "Light absorption and reflection are intensified and controlled by the nature of the medium or through the rendering of textural illusions developed out of the medium itself. Textural concerns and contrasts are as alive as the world around us" (Abbey \& William Fiero, 1986: p. 63).

Fertile fields bring contrast to glistening plains of spawn lava where sturdy plants can be found pushing their 
way from beneath the lava surface to air and light. Sudden rainfalls turn deserts green and bring them to life. And with melted snow streams begin to flow from the mountains. A natural cleavage on a craggy precipice may have a mature, substantial tree or cactus firmly rooted and flourishing. Here we can find the vital energy of life. In a work like van Gogh's "Starry Night" (1889), we can see that "energetically applied impasto pigments awaken passions and affirm life. The odors and textures of paint and canvas linger, stimulate, and involve our other senses” (Abbey \& William Fiero, 1986: p. 71). The vital richness of the natural world and the lasting images of works of art enliven the senses and cultivate a better quality of human life.

In search of geoaesthetic meaning we want to retreat in contemplation to heighten spiritual understanding. Through deepening contemplation we can find a healing process. There are some elements in this process that are physical, emotional, and spiritual. Of course there can be various healing methods and modalities. Healing as a process of getting well is more than eliminating or suppressing symptoms or illness. Healing is a path to restore one's true nature and the meaning of life. Healing through geoaesthetics means to look at the natural order. Looking at and being absorbed in natural phenomena like a sunset, canyon, waterfalls, etc. can facilitate healing. The solitude and silence of primitiveness are to be esteemed, and thus each word uttered is full of meaning and clearly heard. The author thinks, Nietzsche's meaning of the earth, grasped as loyalty to the earth, is grafted into here $^{4}$. The desert is covered with deep stillness, therefore every sound has the significance of being itself. Soundless space and motionless time invite us to contemplation. Those who practice it watch an outcrop of desert rock and project the solid matter into forms and shapes that penetrate the earth and interpenetrate each other. As the earth compresses, folds, pulls open, and buries, solid rock becomes fluid. Mixed by the compound of time, nothing is solid. Time is a path to reach nothingness and finally existence itself. All is dynamic and flowing. Color, line, and texture in geologic phenomena are the fundamentals interacting to build the visual plasticity and meaning of the composition (Abbey \& William Fiero, 1986: p. 4).

Figure 1 of spawn lava shows us abstract and at the same time concrete aspects of rocks. It is transformed into the artistic expression, can be named "Happiness" in Figure 2 of Rita Deanin Abbey (1930-) who is famous for abstract landscape paintings. There are various possibilities to interpret aesthetic meaning from this geological phenomenon. In the sight of "Raindrops" in Figure 3 at San Juan riverside, Utah, we encounter "Moments of Time" in Figure 4 by Rita Deanin Abbey. Moments of time are expressed lying one upon another in raindrops. Raindrops as physical phenomena are well contrasted with moments of time and life as psychological consciousness. I think and imagine original time on the earth could have begun with raindrops.

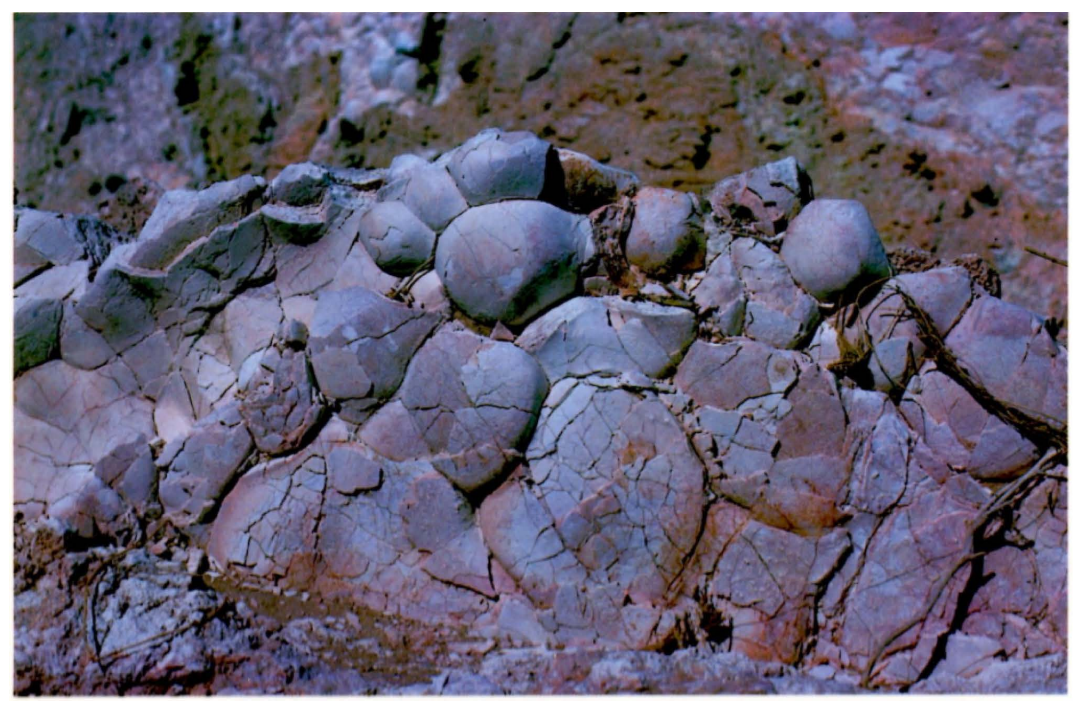

CALVILLE WASH

Figure 1. Jurassic moenkopi: Lake mead national recreation area, Nevada ${ }^{5}$.

\footnotetext{
${ }^{4}$ In Nietzsche’s phrase "der Sinn der Erde” Gary Shapiro draws geophilosophy and geoaesthetics. cf. Shapiro (2004), “Territories, Landscapes, Gardens: Toward Geoesthetics”, Angelaki: Journal of the Theoretical Humanities, 9, 103.

${ }^{5}$ The Moenkopi is a geological formation that is spread widely across New Mexico, northern Arizona, Nevada, southeastern California, eastern Utah, and western Colorado, USA.
} 


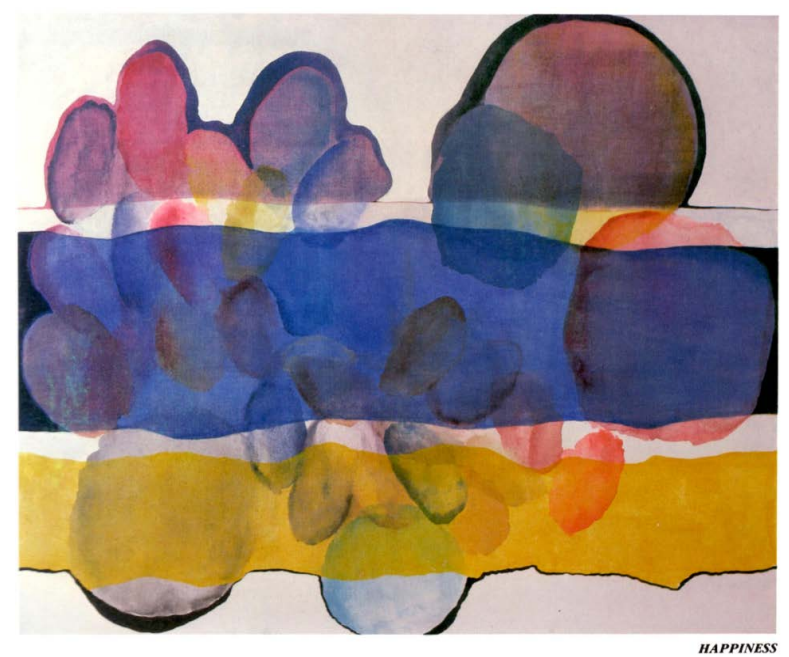

Figure 2. Rita Deanin Abbey: 1977, acrylic on canvas, $50 \times$ 70 inches.

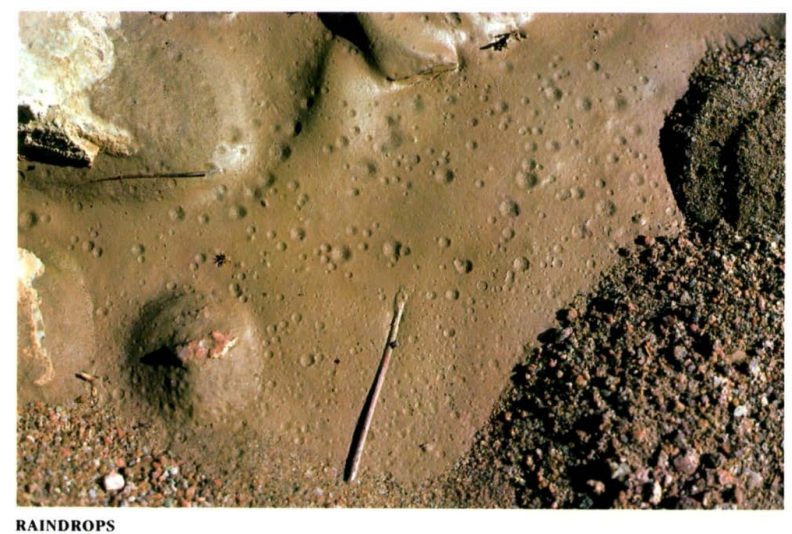

RAINDROPS

Figure 3. San Juan River, Utah.

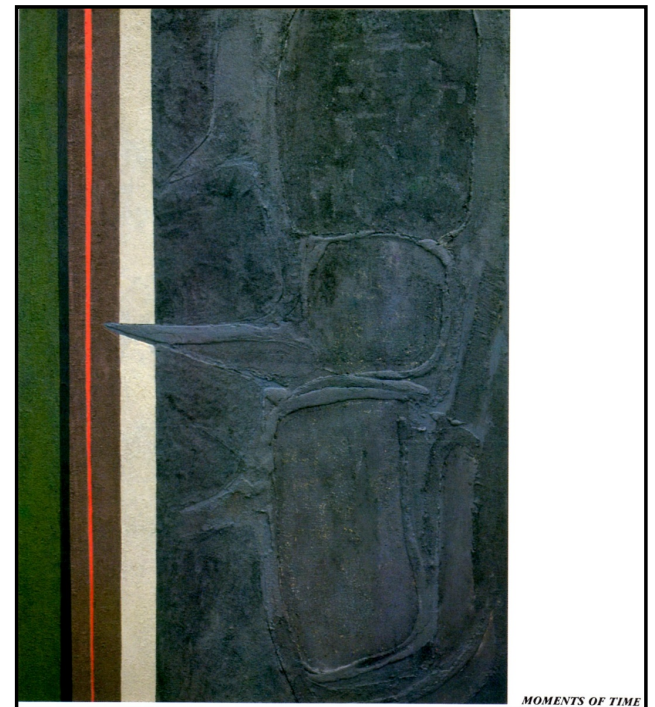

Figure 4. Rita Deanin Abbey: mixed media on canvas, $70 \times$ 50 inches. 
Here, let's give attention to the two terms, geo and bio. Generally speaking, geo is concerned with a lifeless thing, an inanimate or inorganic substance. On the contrary bio is concerned with life, organic substance. Although geological phenomena such as rock, cave, wind, valley, etc. have no lives in themselves, but these have an influence on living things. In this context we have to read bio through geo, and geo through bio. So in geoaesthetics, there is not a separation of geo and bio, but a connection of geo and bio in terms of art. It will be result in an expansion of emotional qualities—so to speak-sympathetic or empathic communication with each other.

\section{Geological Cognition of Nature and Cognition of Nature in Environmental Aesthetics}

The earth has changed continuously since its pristine formation, undergoing some particularly profound transitions and upheavals. The record and document of fossils establish when different kinds of plant and animal groups were propagated and then disappeared on the earth. Since the advent of the human race we human beings have had an enormous impact on the earth. Geologic observations are combined with experiments, measurements, and calculations to develop theories of how natural processes and natural systems operate and interact. In nature, the geoscientist is often confronted only with the results of the experiment and must deduce the materials and processes involved (Montgomery, 1995: pp. 4-8). To understand the concept of nature is complicated by the problems of geologic time and geologic phenomena. In order to make an artistic approach to geologic time and geologic phenomena we groped our way toward the relationship between art and geology in the previous section. In search of the harmony between art and nature, first, we have to rethink the concept of nature.

Allen Carlson, a pioneer in environmental aesthetics and honorary professor of philosophy at the University of Alberta, Canada, argued for the aesthetics of nature. He judges nature as “what it is”. Empirical knowledge informs us of what the object is (Matthews, 2002: p. 39). This judgment can only be acknowledge with a scientific understanding of nature. We appreciate nature as what it in fact is, that is as natural environment. "We must appreciate nature in light of our knowledge of what it is. This knowledge is provided by the natural sciences, especially the environmental sciences such as geology, biology, and ecology. The natural environmental model thus accommodates both the true character of nature and our normal experience and understanding of it” (Carlson, 2002: p. 6).

Before cognitive account of the appreciation of nature, we have to understand that "scientific knowledge is required for the correct appreciation of objects insofar as appreciation involves an element of knowledge, but in categorizing nature, science also focuses our attention on relevant aspects of nature for appreciation” (Matthews, 2002: p. 37). Everything in nature has various aesthetic values under the title of natural beauty or natural landscape. According to Carlson, scientific categories are required in order to appreciate nature correctly, and these make us pay attention to our relevant aspects of nature for appreciation. Scientific knowledge of nature is "only a finer grained and theoretically richer version of our common, everyday knowledge of it, and not something different in kind” (Carlson, 2002: p. 7). Roughly compared, scientific knowledge of geology is shaped by the science of ecology in the meaning of earthly balance through circulating change. Knowledge in art is obtained through self-reflection, self-understanding. According to Roger Paden and others, aesthetics must be based on an evolutionary understanding of nature. Carlson elaborates an ecological approach to environmental aesthetics. We appreciate a natural object in terms of "real nature” (Paden, Harmon, \& Milling, 2012: pp. 124-125). In the aesthetic appraisal of nature we can see it in a "real” eye and with an "ideal” mind. Of course reality can be idealized, or ideality can be realized. Various figures of the reality were converged into the ideality. Sometimes landscapes are idealized on the ground of the real scenes.

In the service of environmental protection and preservation, Carlson provides aesthetic challenges. Carlson's positive aesthetics, his focus on the functionality of human environments, and his integration of aesthetics and ethics have great import for those seeking to use aesthetics to assist in addressing environmental controversies. Discussion about environmental ethics would benefit from taking environmental aesthetics more seriously. Scientific cognition plays a crucial role in Carlson's positive aesthetics, because he derives positive aesthetics from scientific cognition. Positive aesthetic qualities are composed of qualities such as unity, order, harmony, and balance. Ecology shows that qualities such as unity, order, harmony, and balance necessarily characterize ecosystems (Paden, Harmon, \& Milling, 2012: p. 126). Ecology before Ch. Darwin (1809-1882) was based upon an idea of the balance of the nature, but after Darwin this idea was largely abandoned. Ecology has undergone a 
paradigm shift from before Darwin to after Darwin (Paden, Harmon, \& Milling, 2012: p. 128). If evolution is the problem of time, then ecology is the problem of system and structure. Time and system are interdependent of each other.

At the same time nature is partly in a state of confusion, and partly in good order. According to the discordant harmony theory of nature, "nature is not constant in form, structure, or proportion, but changes at every scale of time and space" (Botkin, 1990: p. 62). Ordered or disordered nature is endlessly surprising, always intricate and entrancing. An evolutionary aesthetics must address the possibility of experiencing nature as the sublime. The aesthetic experience of nature is related to the sublimity of nature, and the feeling of the sublime contains a sort of reflective enjoyment in our practical will. The sublime as the extension of our practical will plays a role in connecting the aesthetic with the highest goodness (summum bonum). Allen Carson's positive aesthetics can be surveyed and followed by this summary. Namely, evolutionary aesthetics is based on scientific cognition. It is based on the idea that to appreciate nature properly, we must appreciate it for "what it is" and that science provides us with the best conception of what the object is (Paden, Harmon, \& Milling, 2012: p. 138). It's not a problem of feeling, but a problem of knowing.

The human world is composed of natural and cultural environments. All depictions of nature are not necessarily reflections of reality. Thoughts are projected into nature, and then nature plays the role of mirror to reflect back to us. There are differences between the depiction of nature based on correspondence and construction of the world. Generally speaking, Western thought of nature and Eastern thought of nature are quite different. More simply, Western ideas are an analytic and rational view of nature, and Eastern ideas are an undifferentiated and emotional view of nature. At least in the area of environmental aesthetics, these two ideas are complementarily to each other. Environmental aesthetics is a device to preserve and enjoy nature at the same time, and it's a kind of feedback to nature. Environmental aesthetics focuses on nature's aesthetic value as well as on its environmental implications.

Environmental aesthetics explores the aesthetic meaning and influence of environmental perception and its experience on human life. Arguing for the idea that environment is not merely a setting for people but fully integrated and continuous with us. Arnold Berleant (1932-) explores the aesthetic dimensions of the human-environment continuum in both theoretical terms and concrete situations. According to his environmental aesthetics, he considers the human person as an active contributor in the context that includes and is continuous with the participant. According to him, a person is located in the perceptual center, and belongs to both an individual and a member of a socio-cultural group. Life world is shaped by geographical and cultural factors. In this respect a human being is a double being. Aesthetic experience is always contextual. The aesthetic aspect of any human habitat is an essential part of its desirability. The aesthetic perception of environmental nature shows us the reciprocity that constitutes both the person and his place of living. Genuine beauty lies in coexistence and harmony with the natural environment.

Our aesthetic imagination and freedom are located between environmental nature and human technique. This research is based on the environmental aesthetics including land or earth art. Land art or earth art derives part of its aesthetic appeal from its transient nature (Saito, 2005: p. 171). This project shows the many problems of global environment, human desire, and artist's vision. More than anything else, the author tries to find out a new alternative to explore and restore naturalness in the human mind from a long historical view of geology. We need to understand the principle of naturalness which lies in the change of geologic phenomena. All depictions of nature are not necessarily reflections of reality. Thoughts are projected onto nature, which nature reflects to us. In the context of perfect harmony or coexistence with nature it would be rather good to express naturalness or pan-naturalism ${ }^{6}$.

There are differences between the depiction of nature based on correspondence and the construction of the world. Environmental aesthetics focuses on aesthetic value in nature. It provides the aesthetic reconstruction of landscape and earth art. Gary Shapiro, emeritus professor of philosophy at the University of Richmond, tries to describe the aesthetic sense of nature through designed environment like garden or landscape architecture. According to him, "nature is essentially a social construction, not an absolute given, and points to the specific historical factors that lead to transformation in taste" (Shapiro, 2004: p. 104). Landscape is "a composition of manmade or man-modified spaces to serve as infrastructure or background for our collective existence" (Jackson, 1984: p. 38). Geoaesthetics is the linkage between earth and art in organic unity. For example, we can experi-

${ }^{6}$ Pan-naturalism as a kind of Asian naturalism is a pan-Asian view of the world, nature, religion, and way of life. Once Joseph Needham characterized the Chinese world view as “organic naturalism”. This term seems to be closely related to pan naturalism. 
ence the ancient tradition of rock art, forest art etc. and are inspired by impressive works of art owing to a sense of mystery and awe. The materials in sculpture and wall paintings have geologic significance in primitive way in which forms and patterns of lives were carved. Through geoaesthetics the author explores the desirable forms of natural life on the earth. It will be closely connected to the problems of geological duration and sustainability.

Geological phenomena such as erosion, volcanic ash, basalt volcanic throats are simply extensions of the ordinary descriptions of crevasse, ridge, hummock, and geographical features of mountains (Carlson, 2002: p. 221). As an extension of an enquiry into the laws of nature we can find a role for natural science in our aesthetic appreciation of nature. The appreciation of nature plays a key role in understanding the circumstances of earth's environment. It was discussed in the main concepts of geoaesthetics through geological phenomena and principles. Further, we can realize the possibilities and prospects of geoaesthetics by analyzing and interpreting the materials and works of some leading artists. The aesthetic direction of the geologic earth lies in the meaningful problem for better quality of life, found in contemplation and equilibrium.

\section{Geoaesthetical Approach through Works of Art: Hongtae Kim, Soyoung Chung, Isamu Noguchi, Maya Lin}

Using the geoaesthetic approach the author will review the work of two Korean artists, Hongtae Kim, Soyoung Chung; a Japanese American, Isamu Noguchi; and a Chinese American, Maya Lin. Through four artists the author explores the ultimate purpose of art as a return to natural order. From the works of Hongtae Kim (1947-), who studied at the graduate school of education, Hongik University, Korea, we can experience freedom, contemplative motivation, and homesickness or nostalgia toward something original and primitive. The consistent theme of Hongtae Kim's work is the exploration of primitiveness, which is represented in the child's mind. A child's mind has a primitive tendency, and makes us back to the origin. A child's mind and primitiveness are encountered each other from the viewpoint of simplicity and innocence. All meanings are condensed in simplicity and have strong symbolic character. He scratches and adds parts on picture from the bottom and removes them to uncover the buried figure in the foundation. He gives a sense of tension and draws dynamics through the appropriate division of surface. In addition, he shows us the emergence of root by giving a hint of a symbolic sign. Occasionally, he reveals the hidden figure, which is situated at the base of our consciousness by restraining the expression and organizing the space.

His fundamental pursuit is the harmony of yin and yang principles, embedded in Far-East Asian sentiment. The bright side as yang and the dark side as yin don't have an antipathy to each other, rather they are elements of co-sharing and co-existence. Yin and Yang are both sides of ether or energy as a principle of the universe creation. In Western painting, various elements are put in dialectical conflict and opposition, but for East Asians, they give vitality in harmonization and non-division. Besides, our aesthetic consciousness is contemplative and static because it appears through line rather than plane. Even though line is not dynamic but static, it is original and vital because of its primitiveness. That is the origin of vitality, and life is primitiveness itself.

The primitive figure, carved in the image of child's mind in Figure 5, is composed of spontaneous and unintentional lines. Essentially, the art of the prehistoric age is delineated by line contour. The primitiveness and originality in cave murals, however, introduced by Hongtae Kim reveals dynamic and vital force through strong light that is formed naturally over a long time. This dynamic force is the most basic impulse, possessed by human life. Human beings who are not eternal, pursue the infiniteness, and are basically born with religious inclination. This religious inclination is revealed in naturalness and spirituality. It has also adjusted to the present time. Therefore, we have the expression of primitive force, incantatory image, abstraction and symbolism.

We draw the buried and hidden things in our unconsciousness and transform them into figuration. This partly irregular and inharmonious figuration creates harmony on the whole and shows dynamics. For Hongtae Kim, a child's mind and primitiveness appear as one and the same according to the automatic operating of hand. His automatic hand-working is something related to the spontaneous and unintentional mind. It seems to derive from highly refined professional discipline and long period of practice, however. Hongtae Kim establishes order from chaos, associating with the primitiveness that appears in African sculpture, and mural images. In terms of technique, sometimes, he draws natural feeling of tactile impression by using powdered sand and rice paper. And at other times, he aims at various effects through mixed materials. We can see the possibility of healing through returning to primitiveness and child's mind. Almost all diseases originated from disorder as well as the loss of 


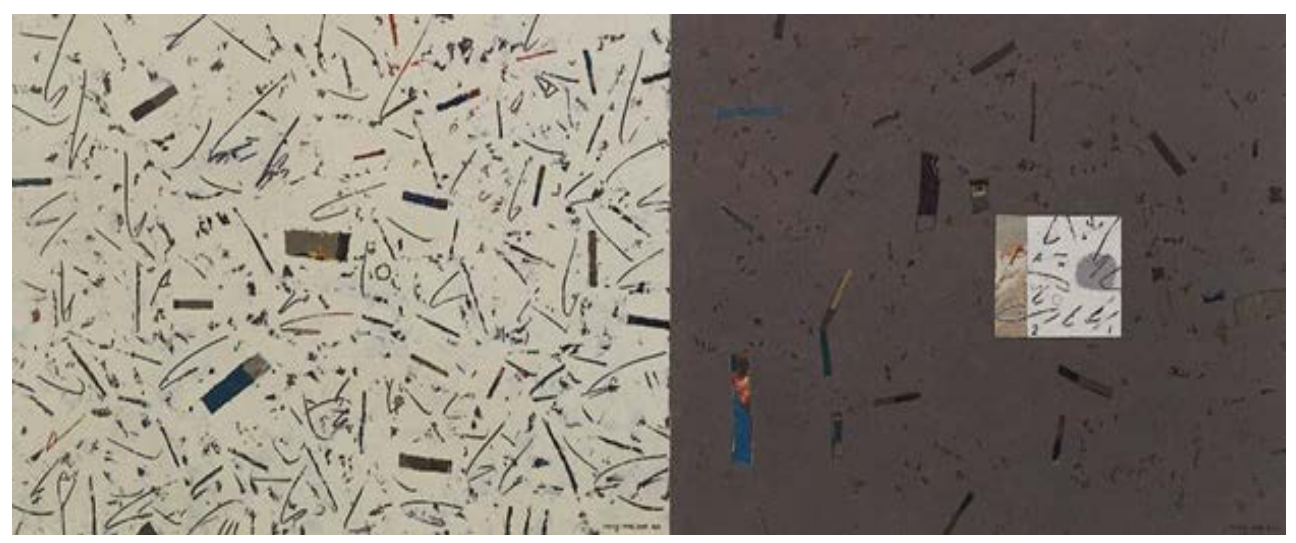

Figure 5. Primitiveness + child’s mind, 2008 (mixed media on Canvas $60.6 \times 145.4 \mathrm{~cm}$ ).

origin. The author hopes that Hongtae Kim's works of art will give us the motivation to suggest a vision of contemplation and healing opportunity in contemporary Korean art? ${ }^{7}$.

Soyoung Chung (1979-), who studied at Ecole Nationale Supérieure des Beaux-Arts de Paris, France, has displayed some remarkable work at shows under titles such as "Innerscape" (Gallery Miss China Beauty, Paris, 2006), “A different Kind of Tension” (Kumho museum of art, Seoul, 2007), "Zero Construction” (Project Space Sarubia, Seoul, 2008), and "On the Ground floor of the Geology Building” (OCI museum of art, Seoul, 2011). She tries to show the interrelation between nature and urbanism. From the ground of observation on the physical transition, her plastic installation changes the established space and creates cyber space. This based on the geological perspective she captures of topographic elements and their structural system in spatiotemporal city life. She displays a series of installations and photographic works, in the format of maps, of the chronological development of the land. In her works like "Waterway" (2011), "Geo-construction" (2011), "Chronology of Construction” (2011), and "Urban geology-building” (Figure 6, 2011) we can watch her topographical consideration and follow after her moulding experiment in the way of avant-garde.

In terms of geo-scape and earth landscape she tries to reconcile the disharmony between order and disorder, cosmos and chaos, man and nature. Her interest originates from the artistic reflection on natural disaster or catastrophe from crustal movements. She seeks to purse an original order or a natural order, of the thing itself. The author thinks geologic formation or layers have a connection with mental topography. Invisible force behind physical appearances is located in the center of the depth of the earth. Natural principle as the order of nature, and natural appearance as chaos, are beautifully coexistent. In her work "Inkdrop" (2007), a falling state is associated with stalactites, which are formed in caves over long periods of time. The ink like water drops and falls from the tip of a stalactite deposit. Soyoung Chung works on sculpture installations deconstructing and reorganizing the structural materials, creating her own peculiar sculptural space. With an aesthetical approach to the physical force of nature, she tries to transform and crystallize the aesthetic equilibrium of gravity. Especially, Figure 6 shows the placement, age and thickness of rock units exposed in the building as if in the geologic formations.

Environmental artist Maya Lin (1959-), who studied architecture and sculpture at Yale University, is immersed in searching for the forces of nature. Her environmental visions reflect the unbroken flow of land and sea, water and wind. Her interest in landscape is influenced and inspired by natural topographies and geologic phenomena. She finds aesthetic inspiration in rock formations, water patterns in watery landscape art and urban situation, solar eclipses and aerial views of the earth. She leads efforts to understand the meaning of the specific site before finding the optimal formation. For her, site specific arts are possible only on the ground of physical surroundings. This site is given to shape a trend toward minimalism and abstraction. Richard Andrews, Director of Henry Art Gallery at Seattle, once said about her, "Maya Lin has an extraordinary ability to convey complex and poetic ideas using simple forms and natural materials." Maya Lin tries to keep in mind a memorial to a vanishing natural world. In her memorial we can read and feel eternity instead of instantaneousness.

In her works "Wave field” (1993-95), “Open-air Peace Chapel” (1988-89) we can feel the exquisite coexis-

${ }^{7}$ Kim, Kwang Myung, 2012, Review on Hongtae Kim’s Solo Exhibition, James Gray Gallery, Nov. 17-Dec. 16, Bergamot Station Art Center, Santa Monica, California, USA. 


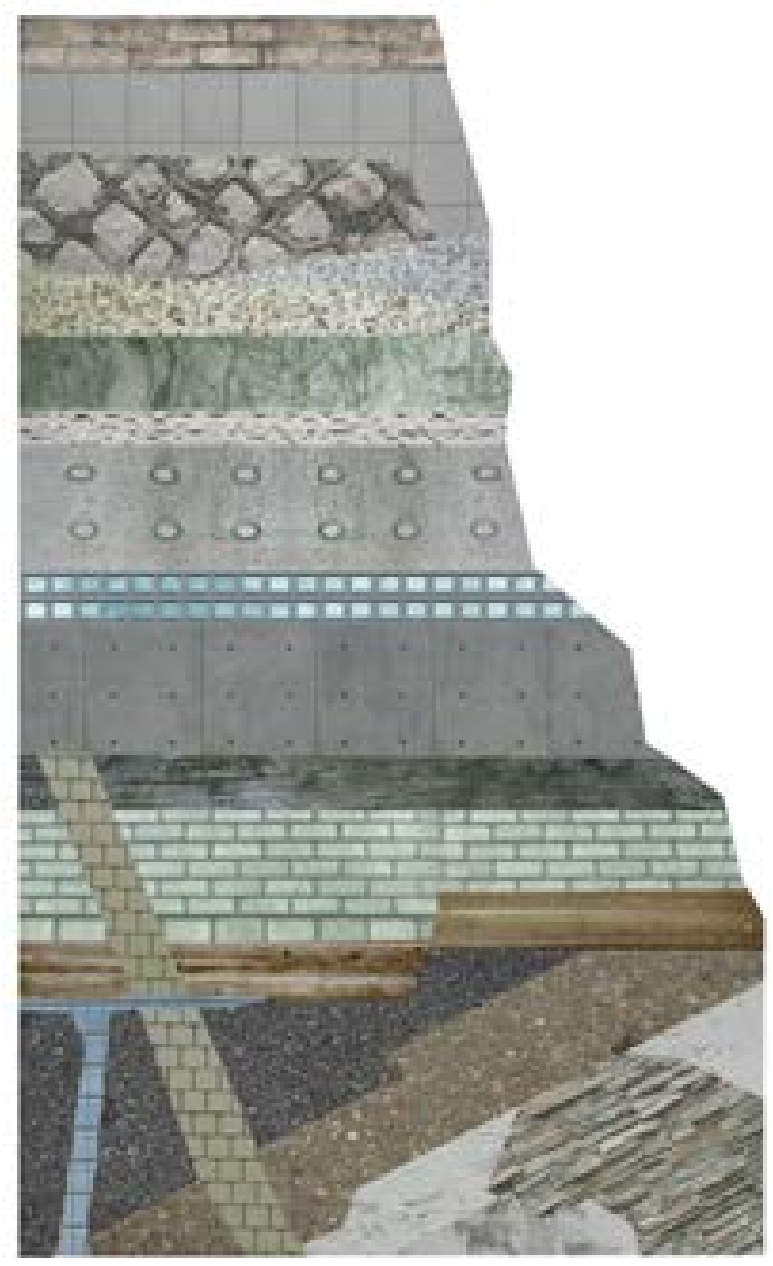

Figure 6. Urban geology-building c-print, $50 \times 73$ cm, 2011.

tence between man and nature. Her inspiration is derived from nature itself like ocean waves, mountains, natural stones, etc. As a landscape sculptor, she is looking for natural beauty from the natural environment. In her exhibition "Three Ways of Looking at Earth" (Pace Wildenstein Gallery, New York, 2009), and especially through her work "Blue Lake Pass" (Figure 7, 2009), she displays her efforts to visualize topographical features that are composed of plane, layer, grid, place, etc. Here we can perceive both earthly dynamics and universal calmness simultaneously.

Isamu Noguchi (1904-1988), who studied at Leonardo da Vinci School of Art in New York City, was a prominent Japanese American artist, and landscape architect. He extended the concept of sculpture with the broad application of new materials like water, light, sound, etc. instead of stone, steel, and wood as traditional materials. He carves stone as a symbol of earth and nature. By him even a piece of stone is connected symbolically to all parts of earth. In his works we can feel the atmosphere of static space and contemplation of nature as well. According to him, the essence of sculpture is really to perceive the space, and the perception of the space is the continuum of our existence. Stone doesn't appear to us as either old or new, but as a primordial element of the earth. Stone plays a role of the primary medium to deliver the generating and disappearing history of the earth. Stone as nature exists where it is, and where we have an experience. Everything can be changed and brought into a formation of a sculpture. With his marvelous capacity of formation he could transform any material, any idea into a sculpture. The visible world enters our consciousness as emotional knowledge with spatial meaning. Through him, the promise of sculpture is to project the inner presence of space into forms that can be recognized as important and meaningful in themselves as a room for contemplation.

Isamu Noguchi designed “The Garden” (Figure 8, 1963) for the Beinecke Plaza as Rare Book and Manuscript 


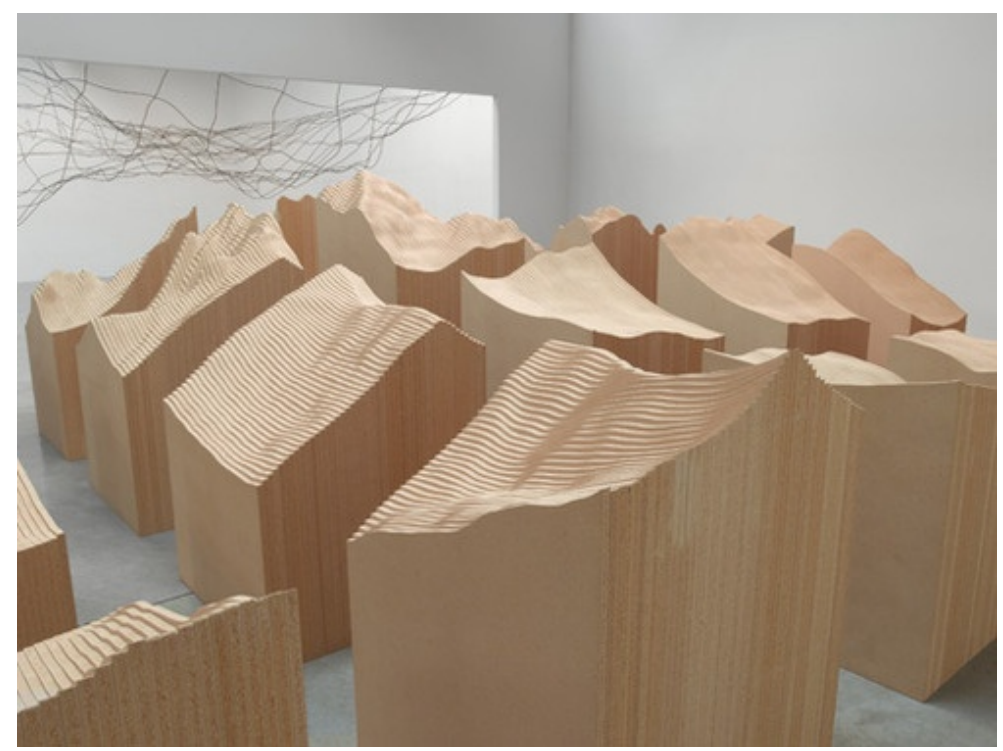

Figure 7. Blue Lake Pass (Pace Wildenstein Gallery, New York, 2009).

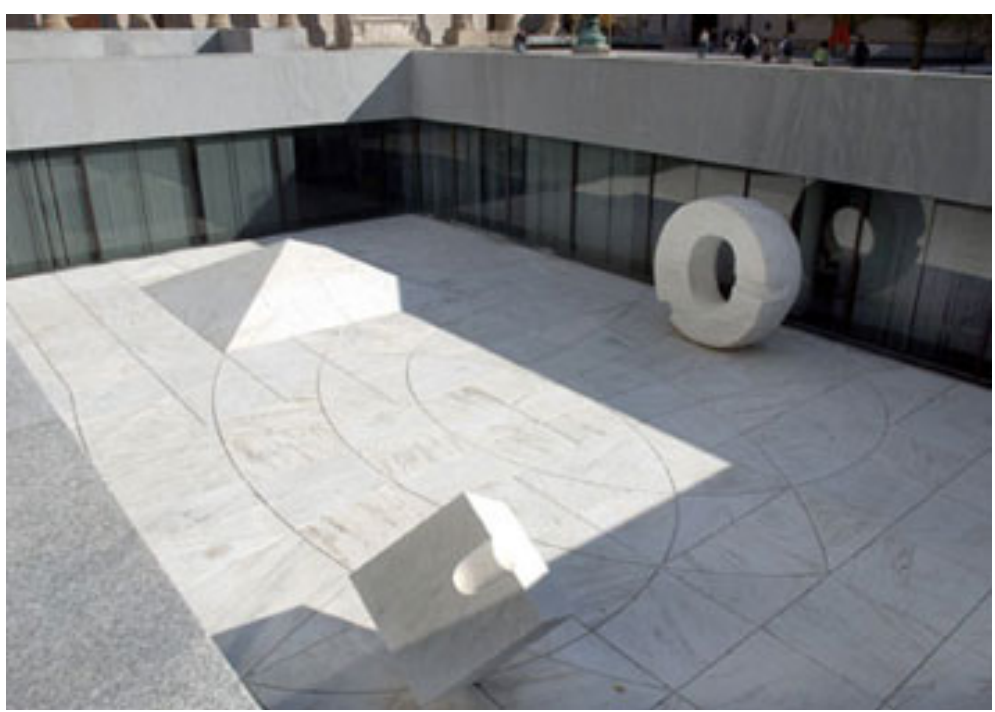

Figure 8. The Garden (pyramid, sun, and cube), 1963, location: Hewitt university quadrangle (Beinecke Plaza).

Library in one of several collaborative efforts with architect Gordon Bunshaft (1909-1990) who was among the first American architects to embrace European Modernism tradition. Garden extends to the library's paneled walls and its sunken courtyard is covered with creamy Vermont marble. And it evokes a contemplative mood. The cold materials of the space inspire not emotion but contemplation, reinforcing a studious atmosphere in the adjacent underground reading room. The mood seems to be similar to that of a Japanese Zen garden ${ }^{8}$, quietly balancing cosmic forces symbolized by the circle filled with sunlight and its energy, the pyramid characterizing the ancient history of the earth. This synthesis of Eastern and Western mood also unites past and future. His ultimate objective is to create and enhance public spaces through sculpture beyond individual space. Although Noguchi's sculptures began as simple geometric shapes, he soon moved toward more organic forms. In the end he merged geometric and organic forms. For him, gardening is considered as sculpturing of space for contemplation. His sustainable gardening work makes it possible to achieve the harmonious existence between man and

${ }^{8}$ Here we can have a sympathetic identification with natural objects. cf. Yuriko Saito, “Japanese Aesthetic Appreciation of Nature”, in Kelly (Ed.), 1998, Encyclopedia of Aesthetics, Vol. 3, (Oxford: Oxford Univ. Press), p. 344. 
nature. Noguchi's works show it to us so well. Owing to Noguchi we can acknowledge the aesthetic sense of nature through gardening landscape.

\section{Conclusion}

In raising the problems and considering the prospects of geoaesthetics, we have considered the relationship between geology and art, the concept of nature in geology and environmental aesthetics. From the long history of geologic earth we can feel both impermanence and permanence at the same time. There must be some reason for this, namely we as human beings live in the moment, and the continuation of moments make long history on the earth. The geological history of earth follows the major events in earth's past based on a system of chronological measurement. This measurement is based on the study of the earth's rock formations and layers. Earth was initially molten due to extreme volcanism and frequent collisions with other bodies. As the surface continually reshaped itself over hundreds of millions of years, continents formed and broke apart. Undergoing repeated cycles of glaciation and thaw, ice can deform, reform, and transform the ground on the earth. And the structures of lava flow are still in progress somewhere on the earth. Deserts give us the feeling of deep stillness. On the horizon of the desert, we can see the connection between earth and sky, linkages of nature and art. Native artists used the geologic materials to create art by carving, scratching, and piling. The materials in sculpture also have geologic significance to create this connection that links earth and art.

The author considers geoaesthetics in relation to environmental aesthetics. The author suggests that approaching geologic formations aesthetically allows a more reciprocal grasp of environmental aesthetics. Natural things or appearances such as light, water, wind, and even climate change, etc. have much influence on the environment and the aesthetic formations of the environmental artist. Illumination of human existence and artistic sublimation give a strong impression on a unique form of contemplation. Contemplation, self-renunciation, and inactivity are the main elements for a geological mind viewed over a long period of time and infinite space. In this context the author briefly suggests the need to differentiate the ways of Western and Eastern approaches to art. As both two sides of the same coin, "being" and "nothingness" are equal in the end, there is really no such thing as a pictorial "nothingness" in the East. Being is only possible in primordial time, that is to say, time itself. History runs its course in time. Thus the development of history falls within time. M. Heidegger (1889-1976) interprets human being as temporality Human being is grounded in the mode of temporalizing in the temporality (Heidegger, 1962: pp. 480-488). With the completion of time, being is transformed into nothingness. "Nothingness" itself is a metaphysical entity. The fundamental thing that the author pursues here is the harmony of man and nature, buried in the geological mind. Man and nature, like yin and yang, don't have an antipathy to each other, rather they are elements for sharing in the long history of earth's formation. For this reason we have to restore naturalness. Naturalness gives us circular vitality and energy. And the origin of vital life lies in geological thinking. In geological thinking as a representative of the appreciation of the nature we find the natural order and natural forces (Carlson, 2002: p. 120).

Naturalness comes from the geological thought behind everything. The contrast between figure and background, as shown in the Gestalt psychology, is well expressed in the relation of man and nature. This research will contribute to the reorientation of art in the face of ecological crisis. Furthermore, this research will draw attention to the significance of the harmonious coexistence of man and nature for a better quality of life on earth. In addition, this research will promote to extend the aesthetic category in the interdisciplinary method of art and geology so that we can solve the questions about sustainable theory in the aesthetic field for the future. Ultimately through this research, the aesthetic appreciation including pan geo-environmental perspective can restore the harmonious status between human beings, art, and nature on the same planet ${ }^{9}$.

\section{References}

Abbey, R. D., \& William Fiero, G. (1986). Art and Geology: Expressive Aspects of the Desert. Layton: Peregrine Smith Books.

Carlson, A. (2002). Aesthetics and the Environment: The Appreciation of Nature, Art and Architecture. London and New York: Routledge.

Edmaier, B., \& Jung-Hüttl, A. (2008). Earthsong. New York: Phaidon.

\footnotetext{
${ }^{9}$ For helpful comments on this article I would like to thank Prof. Mitchell Green and Dr. Cliff Maxwell at the University of Virginia. Above
} all, I am very grateful to Fulbright Foundation for supporting me with Grant. 
Friedl, L., Yuen, K. et al. (2012). Earth as Art. Washington DC: NASA Earth Science.

Green, M. (2008). Empathy, Expression, and What Artworks Have to Teach. In G. L. Hagberg (Ed.), Art and Ethical Criticism (Chapter 4). Oxford: Blackwell. http://dx.doi.org/10.1002/9781444302813.ch4

Heidegger, M. (1962). Being and Time. (trans. John Macquarrie and Edward Robinson). New York: Harper and Row.

Heyd, T. (2003). Rock Art Aesthetics and Cultural Appropriation. The Journal of Aesthetics and Art Criticism, 61, 37-46. http://dx.doi.org/10.1111/1540-6245.00090

Jackson, J. B. (1984). Discovering the Vernacular Landscape. New Haven: Yale Univ. Press.

Kelly, M. (Ed.) (1998). Encyclopedia of Aesthetics (Vol. 3). Oxford: Oxford Univ. Press.

Kim, K. M. (2012). Review on Hongtae Kim’s Exhibition. James Gray Gallery, November 17-December 16, Santa Monica, California: Bergamot Station Art Center.

Matthews, P. (2002). Scientific Knowledge and the Aesthetic Appreciation of Nature. The Journal of Aesthetics and Art Criticism, 60, 37-48. http://dx.doi.org/10.1111/1540-6245.00050

Montgomery, C. W. (1995). Environmental Geology (4th Ed.). Dubuque, Iowa: Wm. C. Brown Publishers.

Paden, R., Harmon, L. K., \& Milling, C. R. (2012). Ecology, Evolution, and Aesthetics. British Journal of Aesthetics, 52, 123-139. http://dx.doi.org/10.1093/aesthj/ays001

Plessner, H. (1981). Kants System unter dem Gesichtspunkt einer Erkenntnistheorie der Philosophie. Frankfurt: Suhrkamp.

Saito, Y. (2005). The Aesthetics of Weather. In A. Light, \& J. M. Smith (Eds.), The Aesthetics of Everyday Life. New York: Columbia University Press.

Saito, Y. (2010). Future Directions for Environmental Aesthetics. Environmental Values. Center Conway, NH: The White Horse Press.

Seel, M. (1998). Aesthetics of Nature and Ethics. In M. Kelly (Ed.), Encyclopedia of Aesthetics (Vol. 3). Oxford: Oxford Univ. Press.

Shapiro, G. (2004). Territory, Landscape, Garden toward Geoaesthetics. Angelaki: Journal of the Theoretical Humanities, 9, 103. 
Scientific Research Publishing (SCIRP) is one of the largest Open Access journal publishers. It is currently publishing more than 200 open access, online, peer-reviewed journals covering a wide range of academic disciplines. SCIRP serves the worldwide academic communities and contributes to the progress and application of science with its publication.

Other selected journals from SCIRP are listed as below. Submit your manuscript to us via either submit@scirp.org or Online Submission Portal.
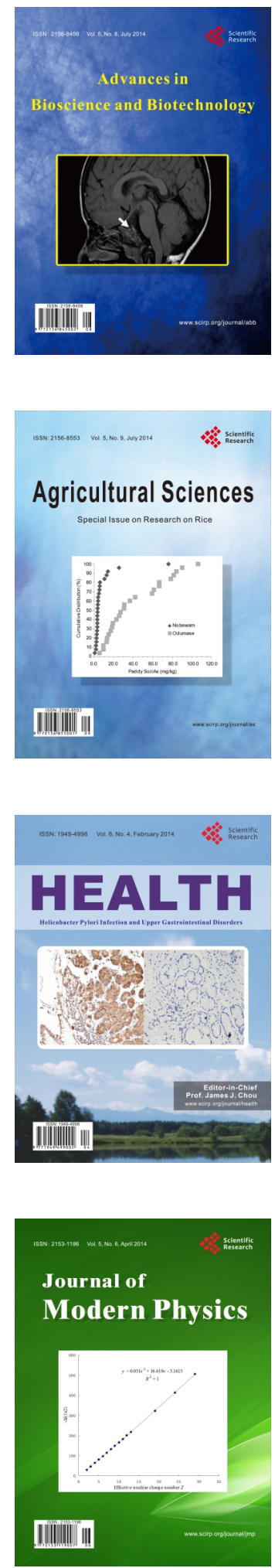
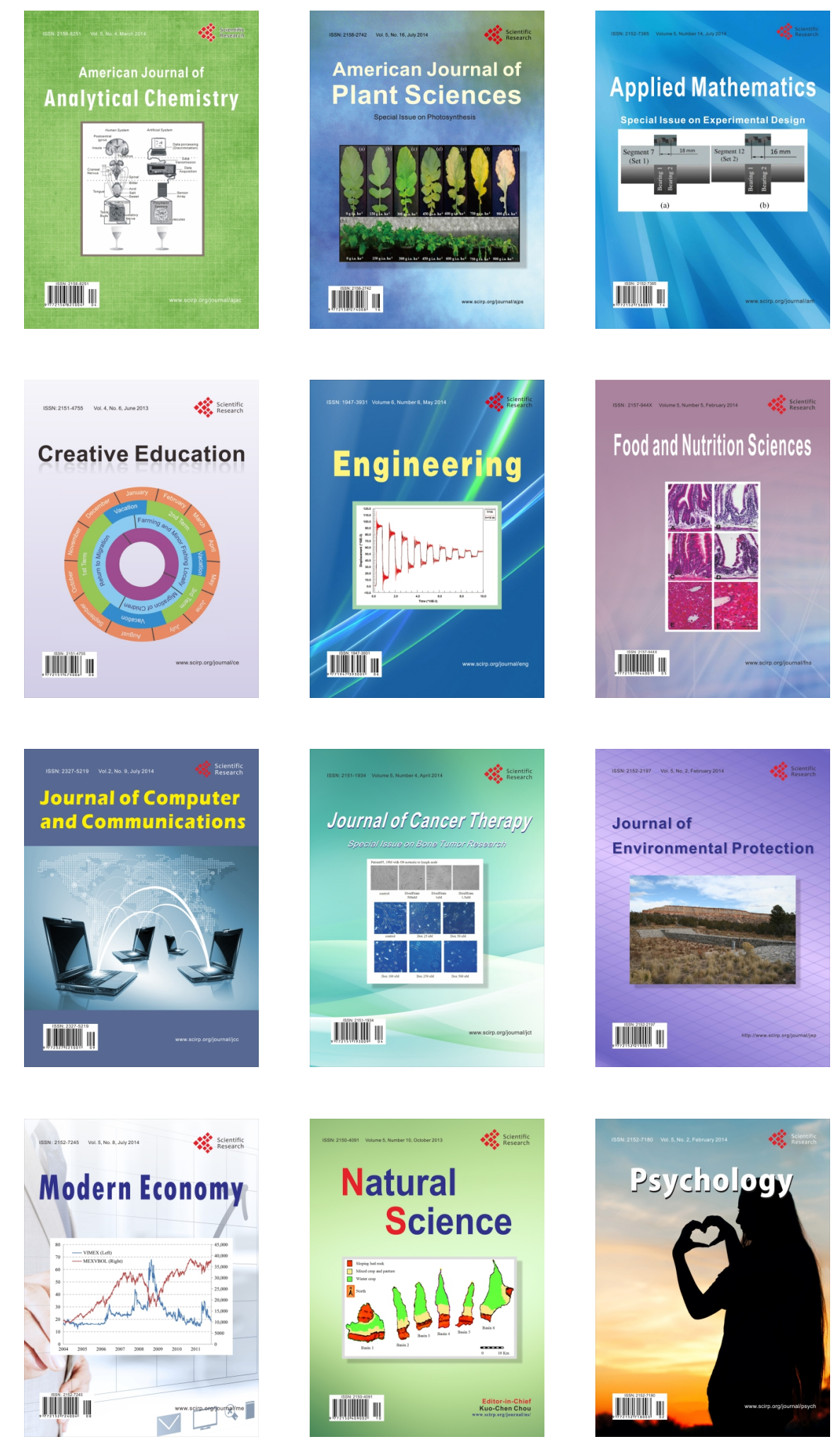